\title{
Experimental study on Rankine cycle evaporator efficiency intended for exhaust waste heat recovery of a diesel engine
}

\author{
Nikolay Milkov ${ }^{1, *}$, Quentin Danel ${ }^{2}$, Plamen Punov ${ }^{1}$, Christelle Perilhon ${ }^{2}$, Pierre Podevin ${ }^{2}$, and Teodossi Evtimov ${ }^{1}$ \\ ${ }^{1}$ Technical University - Sofia, Department of Internal Combustion Engines, Automobiles and Transport, 1000 Sofia, Bulgaria \\ ${ }^{2}$ Conservatoire National des Arts et Métiers, CMGPCE, 292 rue Saint Martin, 75003 Paris, France
}

\begin{abstract}
The paper pressents an experimental study of Rankine cycle evaporator efficiency. Water was chosen as the working fluid in the system. The experimental test was conducted on a test bench equipped with a burner charged by compressed fresh air. Generated exhaust gases parameters were previously determined over the diesel engine operating range (28 engine operating points were studied). For each test point the working fluid parameters (flow rate and evaporating pressure) were varied. Thus, the enthalpy flow through the heat exchanger was determined. Heat exchanger was designed as 23 helical tubes are inserted. On the basis of the results, it was found out that efficiency varies from $25 \%$ to $51,9 \%$. The optimal working fluid pressure is 20 bar at most of the operating points while the optimum fluid mass flow rate varies from $2 \mathrm{~g} / \mathrm{s}$ to $10 \mathrm{~g} / \mathrm{s}$.
\end{abstract}

\section{Introduction}

Waste heat recovery by means of Rankine cycle is a promising approach for achieving significant reduction in fuel consumption and $\mathrm{CO}_{2}$ emissions of the vehicles. The efficiency of Rankine cycle strongly depends on the heat transfer in heat exchanger from exhaust gases to the working fluid.

There are many types of heat exchangers depends on their design. As a function of flow direction they can be separated as: co-current and counter-current. Usually the opposite direction of the fluids (counter-current) leads to higher efficiency. According to the design, heat exchangers can be classified as: shell and tube, spiral tube, finned plate and finned tube heat exchangers $[1,2]$. In order to select suitable heat exchanger many parameters have to be taken into account such as: heat exchange surface, operating pressure, operating temperature, mass flow rates, hydraulic losses, size, mass, price and etc. Usually, the higher heat exchange surface and the minimum heat exchange resistance are preferable.

Glavatskaya, in [3] presented a comparative study of the technologies for the Rankine cycle evaporator. In this study three heat exchangers were recommended: plate and fins exchanger, pipe bundle type exchanger and shell and tube exchanger. As a result of this study it has been found that for the same transferred energy, the tube bundle type technology is the most compact and it offers a moderate exhaust gas pressure drop. As a part of this study two types of condensers have been selected for use in a Rankine loop: a tube and fin exchanger for external air cooling, and a plate exchanger for using glycol water as a well cold. The comparative study of the condensers on these operating conditions showed that the water-glycol cooled plate condenser has the best ratio between size and performance. In the work of Danel [4] was presented experimental and numerical study of a heat exchanger constructed by 23 helical tubes situated along the evaporator which provides the heat exchange surface approximately $1,8 \mathrm{~m}^{2}$. The results show that its efficiency varies from $30 \%$ to $42 \%$.

On the base of the reviewed articles [5-13] the tube heat exchangers were most commonly used. The efficiency varied from $24 \%$ to $76 \%$ depending on the design and operating conditions.

\section{Experimental set-up and methodology}

\subsection{Experimental set-up}

In order to conduct experimental research a test bench of Rankine cycle waste heat recovery system was used. The cycle including the following components: burner; heat exchanger (evaporator); cooler (condenser); reservoir and pump (Fig. 1).

All of the components are connected by means of stainless steel tubes. The test equipment consists of two fluid paths: the first is the exhaust gases flow which comes from the burner and goes through the heat exchanger while the second is working fluid flow through the pump, heat exchanger, cooler and reservoir. Water was used as working fluid in this cycle. However, the test equipment can work with different fluids such as ethanol and etc. The working fluid was cooled down as cold water with variable mass flow rate circulates through the condenser. In this test bench an expansion machine was not used. In order to keep the working fluid pressure an electro vane was used.

* Corresponding author: nikolay.milkov@,tu-sofia.bg 


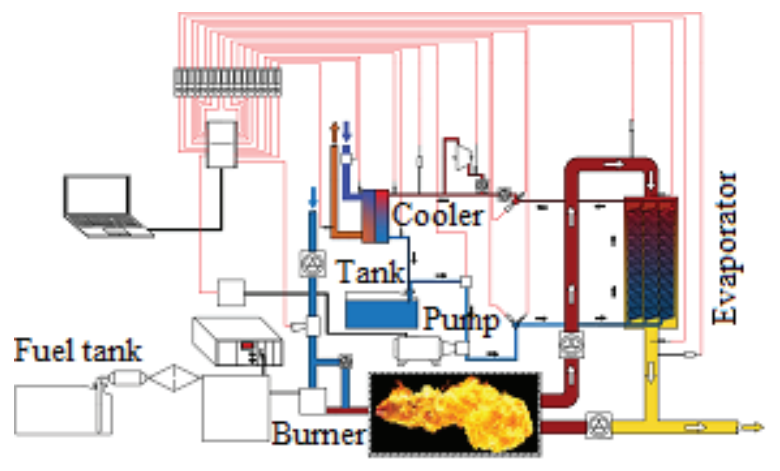

Fig. 1. Experimental test bench.

The purpose of the burner is to produce exhaust gases with the same parameters of that produced by a modern diesel engine. The burner operates with diesel fuel while the fresh air comes from a compressor. The enthalpy of exhaust gases can be varied by variation of the fuel and air mass flow in the burner. In order to simulate various combination of temperature and mass flow rate a part of fresh air passes outside the burner. Fresh air mass flow is setting by a vane, the main part of this flow goes to the burner and a second part is mix with burned gas to set the temperature. The fuel is injected in the burner by a pump and an internal by-pass is used to set the fuel mass flow.

The test bench is equipped with thermo-couples type $\mathrm{K}$ for measuring the temperature of the working fluid and exhaust gases, pressure sensors for acquiring the pressure drop on the exhaust gases flow and working fluid through the heat exchanger as well as the pressure in the condenser. Mass flow sensors are used for measuring the mass flow rate of working fluid, cooling water as well as of the air and fuel through the burner. In order to collect the experimental data a National Instruments DAQ model 6218 and a LabView based program were used.

For experimental test a counter-current flow heat exchanger was developed. The working fluid circulates inside the helical tubes situated along the evaporator. The number of tubes is 23 which provides the heat exchange surface approximately $1,8 \mathrm{~m}^{2}$.

\subsection{Methodology}

The experimental study was carried out with the exhaust gas parameters (temperature and mass flow) previously determined at different operating points of the diesel engine. Thus, 28 engine operating points were selected (Fig. 2). For each point the exhaust gases temperature $\left(T_{g}\right)$ and mass flow were measured on the engine test bench at the exhaust system 1,5 $\mathrm{m}$ downstream the turbocharger.

The burner injector can operate with four orifices with different size. Therefore, the burner is limited in terms of the fuel flow rate. For that reason, within the engine operating area with brake mean effective pressure (BMEP) of less than 6,6 bar, the fuel flow rate did not allow a combustion process with demanded exhaust gas parameters (temperature and flow). Thus, the engine operating field with BMEP below 6,6 bar was not studied.

The experimental test was carried out as follows:

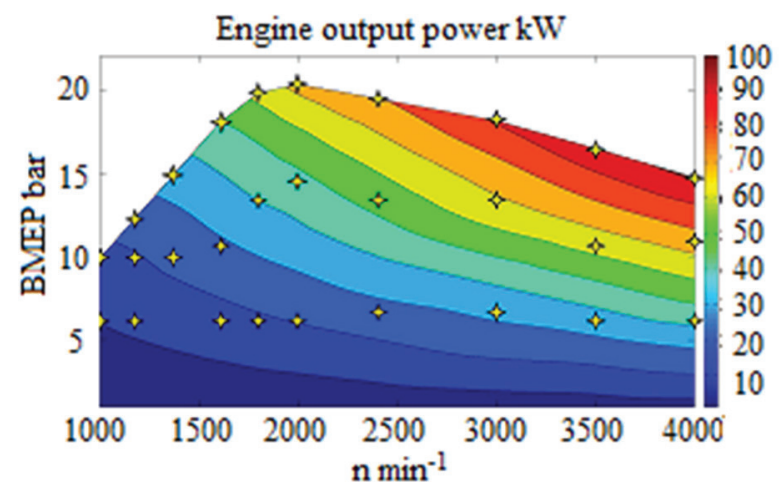

Fig. 2. Distribution of the studied points on the engine operating map.

- On the Rankin cycle based test bench, the exhaust gases with the same temperature and mas flow rate, determined for each of the selected engine operating point (Fig. 2) were simulated.

- The flow rate and pressure of the working fluid in the system were varied. The mass flow rate of the working fluid $\left(m_{w f}\right)$ was set up to 2, 4, 6, 8 and $10 \mathrm{~g} / \mathrm{s}$, while for the pressure $\left(p_{w f}\right)$ was $5,10,15$ and 20 bar. These values were selected in order to meet the safety requirements of the system and to meet the requirements of the experimental test bench.

- After establishing the steady heat transfer in the Rankin cycle for each studied point, the temperature and pressure of the working fluid, the exhaust gases temperature as well as the mass flow rate of both fluids were measured.

The results which are close to the saturation curve or even on the left side of the curve are not presented, because in these cases the working fluid is not completely evaporated. For this reason, results are not presented for the engine rotation speed $(n)$ below $1200 \mathrm{~min}^{-1}$ and for some points with low engine load.

\section{Experimental results}

Results present the variation of the heat exchanger outlet exhaust gases temperature and outlet working fluid temperature as a function of the working fluid pressure. Here, the results at maximum engine load and speed of $1200,2000,2800,3500$, and $4000 \mathrm{~min}^{-1}$ are presented.

Therefore, the variation of the exhaust gases temperature at the outlet of the heat exchanger (evaporator) as a function of the working fluid pressure are presented in the Fig. 3 to 7.

The variation of the exhaust gas temperature (Fig. 3) is within the range of $216{ }^{\circ} \mathrm{C}$ to $236{ }^{\circ} \mathrm{C}$. The maximum value is at 20 bar working fluid pressure.

The exhaust gases temperature (Fig. 4) varies from $242{ }^{\circ} \mathrm{C}$ to $250{ }^{\circ} \mathrm{C}$. The maximum value was obtained at 5 bar operating pressure.

In Fig. 5 the exhaust gases temperature at the outlet of the evaporator ranges from $311{ }^{\circ} \mathrm{C}$ to $322{ }^{\circ} \mathrm{C}$. The maximum value was measured at 5 bar operating pressure. 


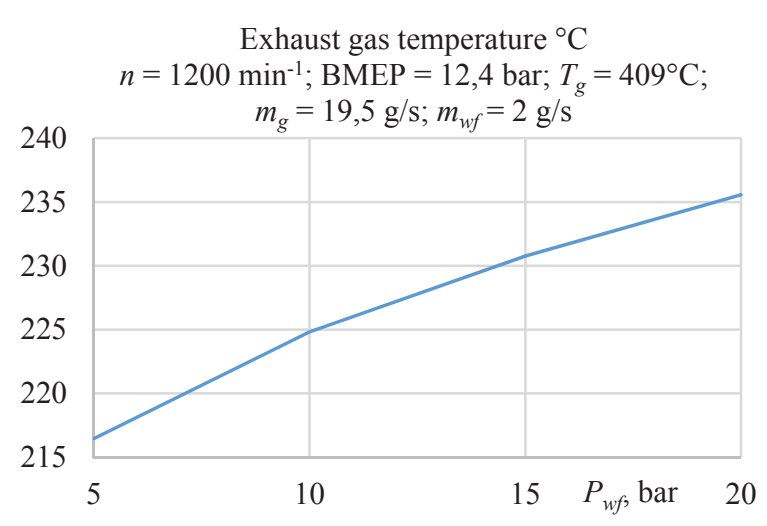

Fig. 3. Exhaust gas temperature after evaporator.

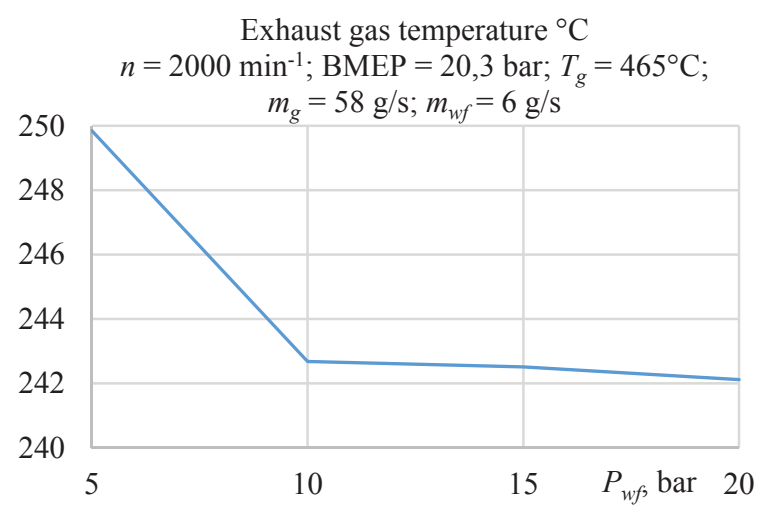

Fig. 4. Exhaust gas temperature after evaporator.

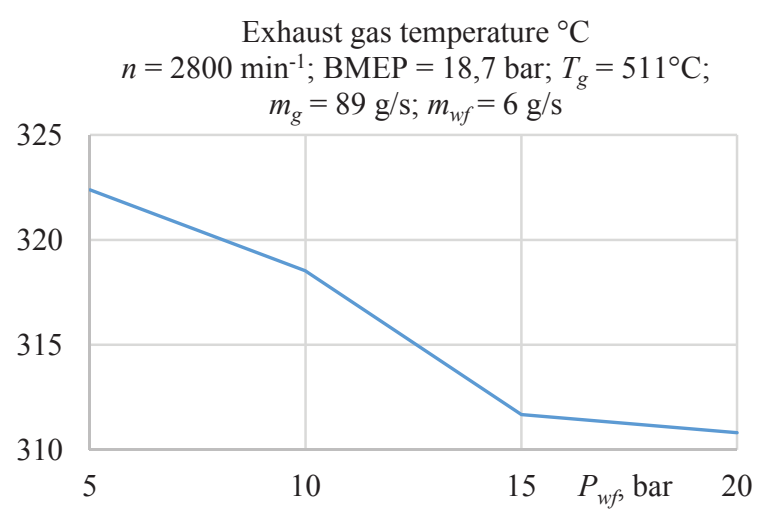

Fig. 5. Exhaust gas temperature after evaporator.

The temperature variation in Fig. 6 is within the range of $271{ }^{\circ} \mathrm{C}$ to $281{ }^{\circ} \mathrm{C}$. The maximum value was measured at working fluid pressures 10 bar and 15 bar.

In Fig. 7 the exhaust gases temperature at the outlet of the evaporator ranged from $273{ }^{\circ} \mathrm{C}$ to $281{ }^{\circ} \mathrm{C}$. The maximum value is at a working fluid pressure of $10 \mathrm{bar}$.

In Fig. 8 to 12 , the variation of the working fluid temperature at the outlet of the evaporator depending on the operating pressure in the system is presented.

The variation of the working fluid temperature at the outlet of the evaporator shown in Fig. 8 is within the range of $155^{\circ} \mathrm{C}$ to $215^{\circ} \mathrm{C}$. The values varied as a function of the pressure of the working fluid. For each pressure value the temperature is close to evaporation temperature, which means low degree of overheating. It can be explained by the low exhaust temperature at this operating point.

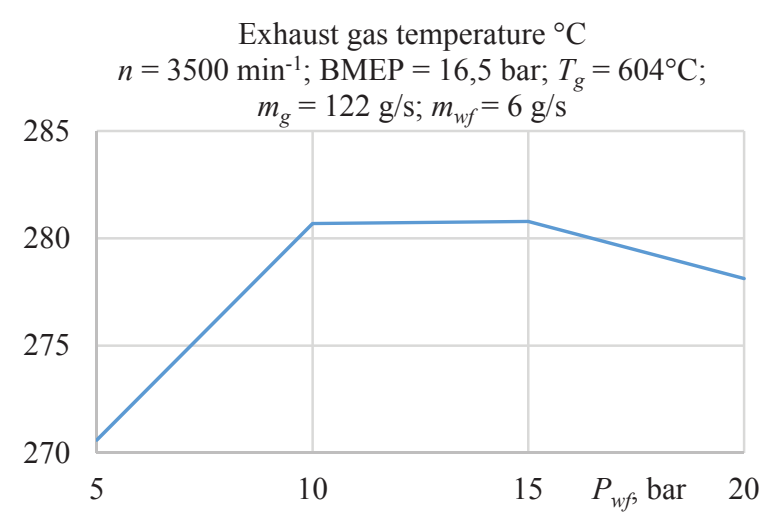

Fig. 6. Exhaust gas temperature after evaporator.

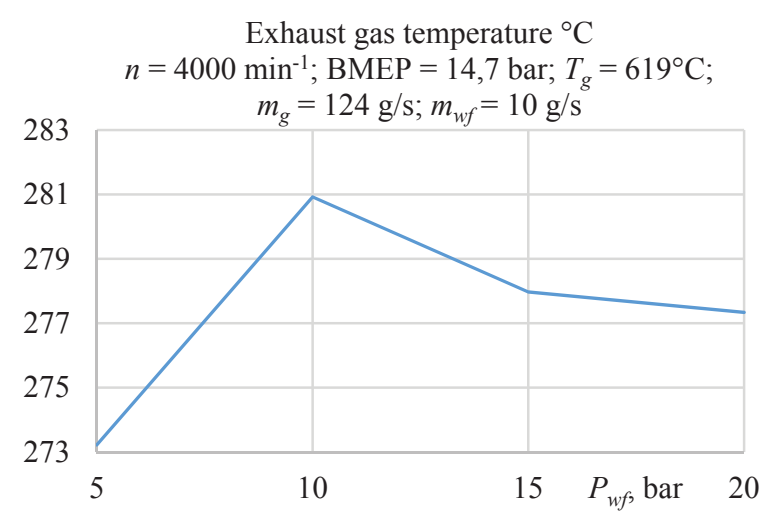

Fig. 7 Exhaust gas temperature after evaporator.

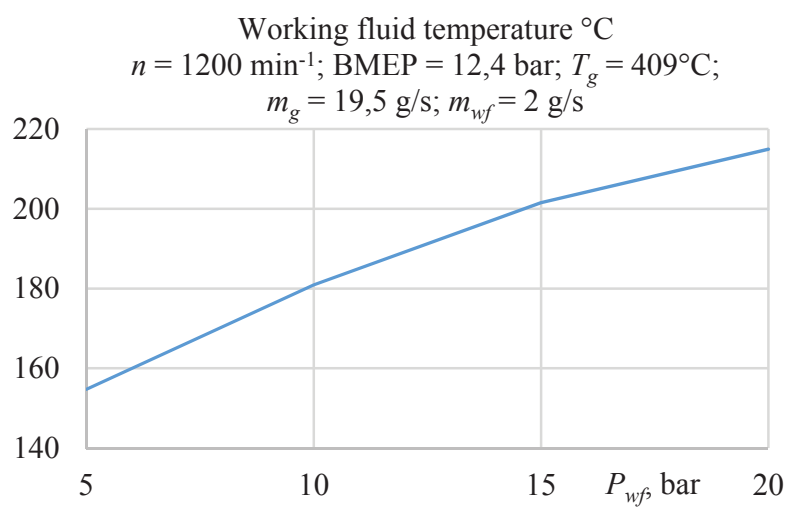

Fig. 8. Working fluid temperature after evaporator.

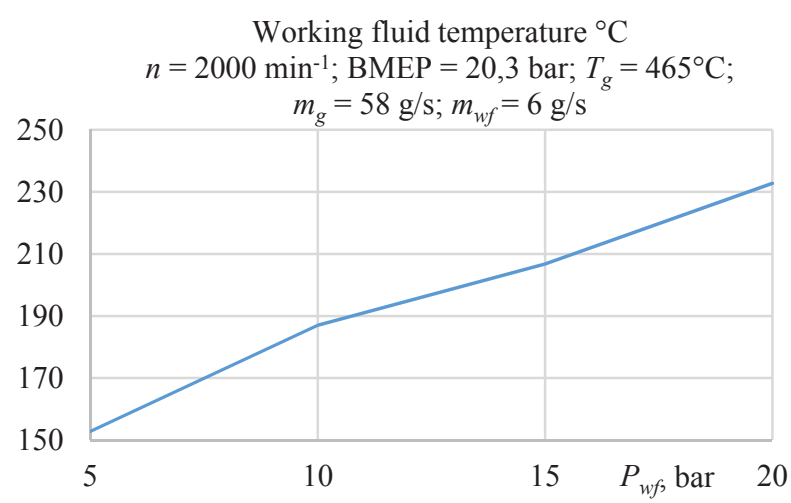

Fig. 9. Working fluid temperature after evaporator.

The temperature of the working fluid presented in Fig. 9 varies from $154{ }^{\circ} \mathrm{C}$ to $232{ }^{\circ} \mathrm{C}$. In this engine operating 
point the exhaust gases enthalpy is higher which lead to higher working fluid temperature.

The temperature presented in Fig. 10 is in the range of $161{ }^{\circ} \mathrm{C}$ to $300{ }^{\circ} \mathrm{C}$. There is a significant increase in the working fluid temperature at this engine operating point. Here, it can be stated that the full evaporation of the fluid occurs.

The results in Fig. 11 present that the temperature varies from $159{ }^{\circ} \mathrm{C}$ to $240{ }^{\circ} \mathrm{C}$.

Working fluid temperature ${ }^{\circ} \mathrm{C}$ $n=2800 \mathrm{~min}^{-1} ; \mathrm{BMEP}=18,7 \mathrm{bar} ; T_{g}=511^{\circ} \mathrm{C}$;

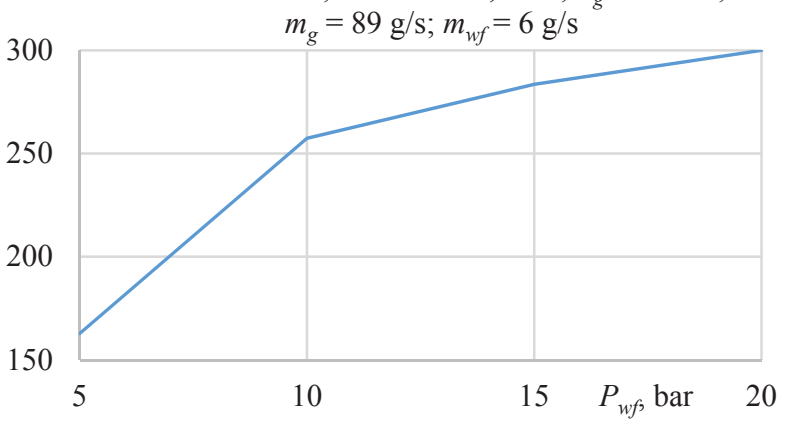

Fig. 10. Working fluid temperature after evaporator.

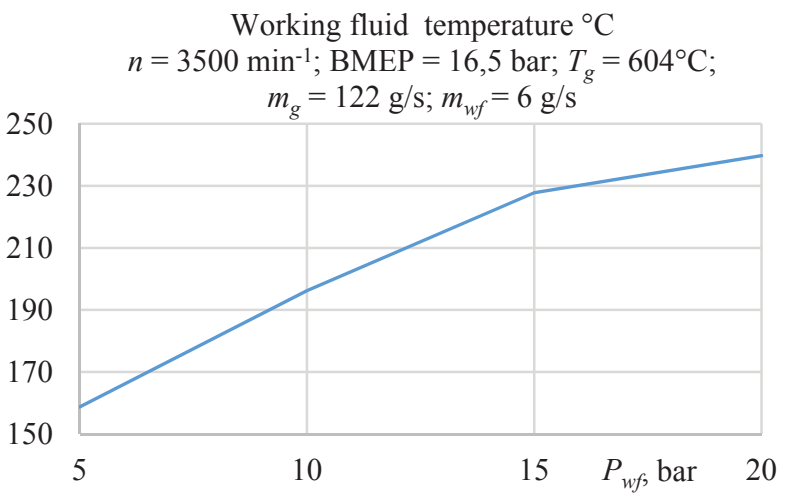

Fig. 11. Working fluid temperature after evaporator.

The results in Fig. 12 present that the outlet working fluid temperature varies from $156{ }^{\circ} \mathrm{C}$ to $234{ }^{\circ} \mathrm{C}$.

The results obtained from the test were used in order to assess the heat transfer from the exhaust gases to the working fluid and then the efficiency of the heat exchanger was calculated.

The evaporator efficiency is calculated as follows:

$$
\eta_{H E}=\frac{m_{w f \cdot} \cdot\left(h_{f s}-h_{f e}\right)}{m_{g} \cdot c_{p g}\left(T_{g e}-T_{0}\right)} \cdot 100, \%,
$$

where $m_{w f}$ - mass flow rate of the working fluid, $\mathrm{g} / \mathrm{s}$; $m_{g}$-mass flow rate of the exhaust gases, $\mathrm{g} / \mathrm{s} ; h_{f s}-$ specific enthalpy of the working fluid at the outlet, $\mathrm{kJ} / \mathrm{kg}$; $h_{f e}$ - specific enthalpy of the working fluid at the inlet, $\mathrm{kJ} / \mathrm{kg} ; c_{p g}-$ specific heat capacity of the exhaust gases, $\mathrm{J} / \mathrm{kg} . \mathrm{K} ; T_{g e}-$ temperature of the exhaust gases at the inlet, $\mathrm{K} ; T_{o}-$ ambient temperature, $\mathrm{K}$.

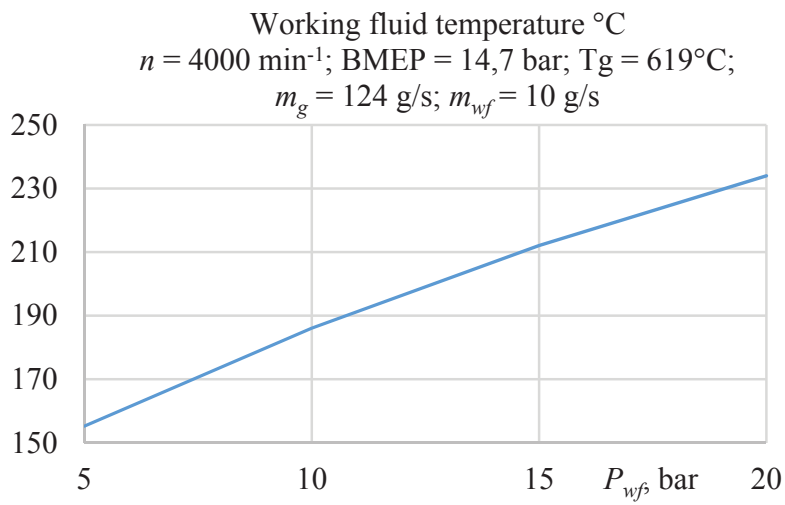

Fig. 12. Working fluid temperature after evaporator.

Fig. 13 to 17 show the efficiency of the evaporator in that operating points in which the working fluid temperature and exhaust gases temperature at the evaporator outlet are presented in the previous part. The efficiency is presented as a function of working fluid pressure.

In Fig. 13 the efficiency of the evaporator slightly decreases as increasing the working fluid pressure. Here, the efficiency ranged from $40 \%$ to $44 \%$.

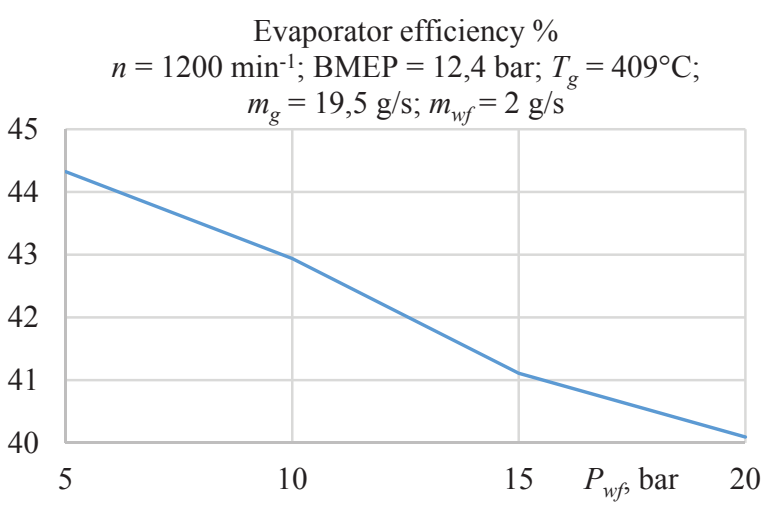

Fig. 13. Evaporator efficiency.

The efficiency of the evaporator at the engine operating at $2000 \mathrm{~min}^{-1}$ (Fig. 14) is in range from 49,6\% to $50,8 \%$. The maximum was observed at working fluid pressure of 10 bar.

In Fig. 15, the efficiency varied from $34,4 \%$ and 36,8 $\%$, the maximum value corresponds to a pressure of 20 bar.

The efficiency of the evaporator shown in Fig. 16 is within the range of $32,9 \%$ to $35,3 \%$, with the maximum value at 5 bar operating pressure.

The efficiency of the evaporator at $4000 \mathrm{~min}^{-1}$ and full engine load (Fig. 17) varied from $34,4 \%$ to $36,1 \%$, the maximum value was observed at a working fluid pressure of 5 bar.

At full engine load the evaporator efficiency ranged from $32 \%$ to $50,8 \%$. The maximum value was observed at engine operating point corresponds to maximum engine at engine speed of $2000 \mathrm{~min}^{-1}$ and BMEP of 20,3 bar. 


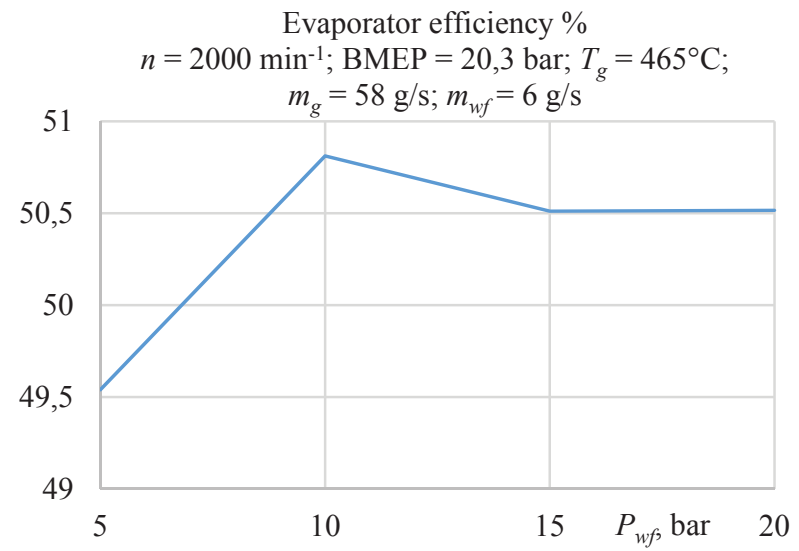

Fig. 14. Evaporator efficiency.

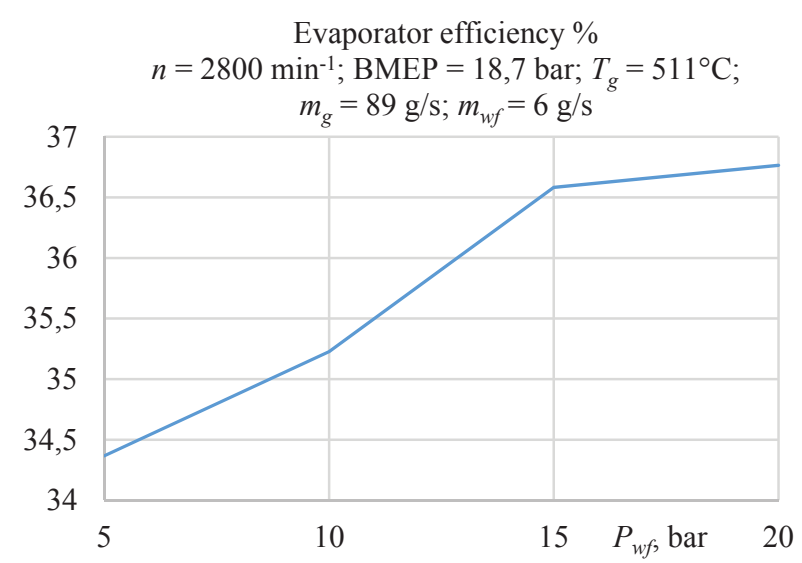

Fig. 15. Evaporator efficiency.

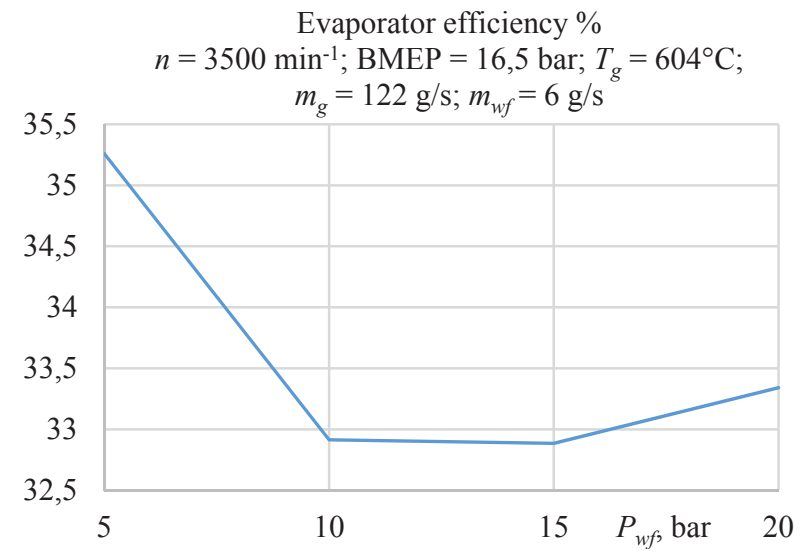

Fig. 16. Evaporator efficiency.

Fig. 18 shows the evaporator efficiency in a part of the engine operating map. Evaporator efficiency was estimated to be within the range from $24,8 \%$ to $51,9 \%$, with the maximum value at $2000 \mathrm{~min}^{-1}$ and BMEP of 15,2 bar. The minimum value was achieved at $3500 \mathrm{~min}^{-1}$ and 6,6 bar BMEP. On the base of the results the evaporator efficiency is higher at the engine operating range with maximum efficiency of the engine.

Fig. 19 shows the variation of the thermal power of the working fluid after the evaporator, corresponding to the maximum values of the evaporator efficiency, presented in the engine operating map.

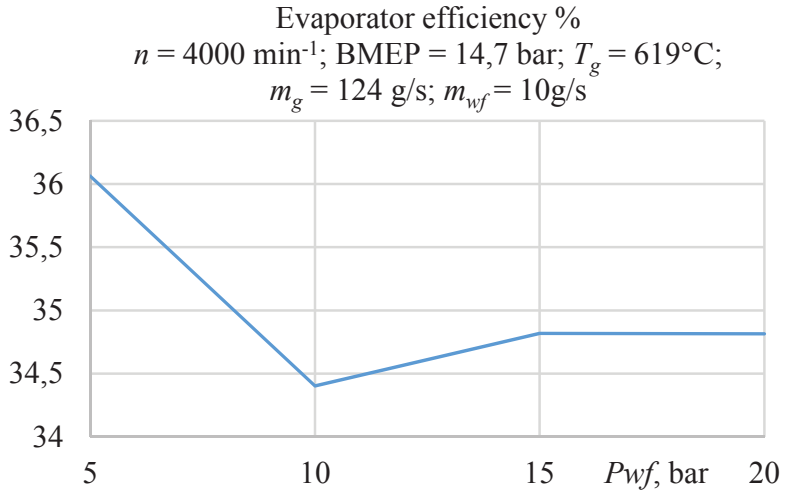

Fig. 17. Evaporator efficiency.

The thermal power of the working fluid at the outlet of the evaporator increases as increasing the engine speed and load. The maximum power of the working fluid was estimated to be $35 \mathrm{~kW}$ at the engine operating corresponds to maximum engine power (4000 $\mathrm{min}^{-1}$ and BMEP 14,7 bar).

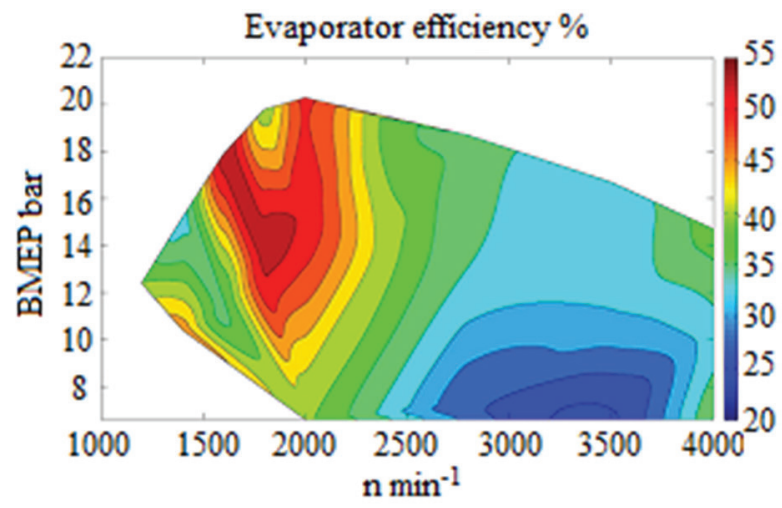

Fig. 18. Evaporator efficiency over the engine operating map.

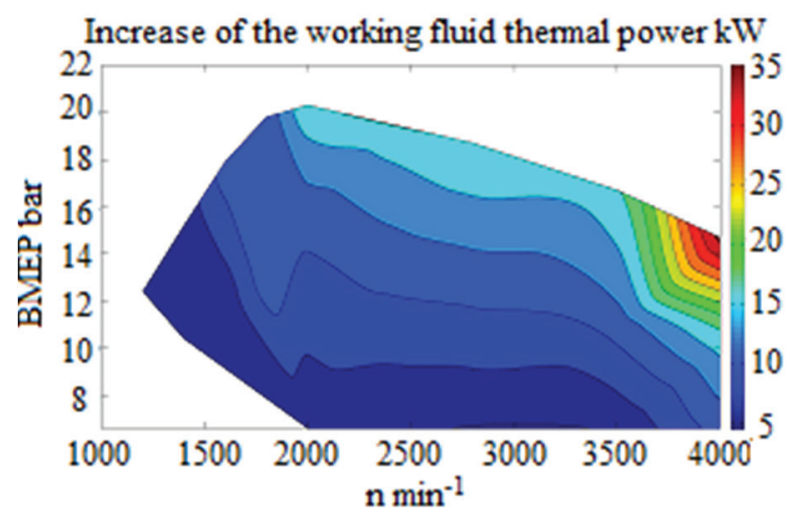

Fig. 19. Working fluid thermal power at evaporator outlet.

On the basis of this experimental study, the optimal value for the working fluid mass flow and pressure in the Rankine cycle were determined.

Fig. 20 presents the variation of the working fluid mass flow that corresponds to the maximum efficiency of the evaporator. The flow rate of the working fluid varies from $2 \mathrm{~g} / \mathrm{s}$ to $10 \mathrm{~g} / \mathrm{s}$ The mass flow rate increases as increasing of the load and engine speed. The maximum value was observed at the maximum power of the engine. 


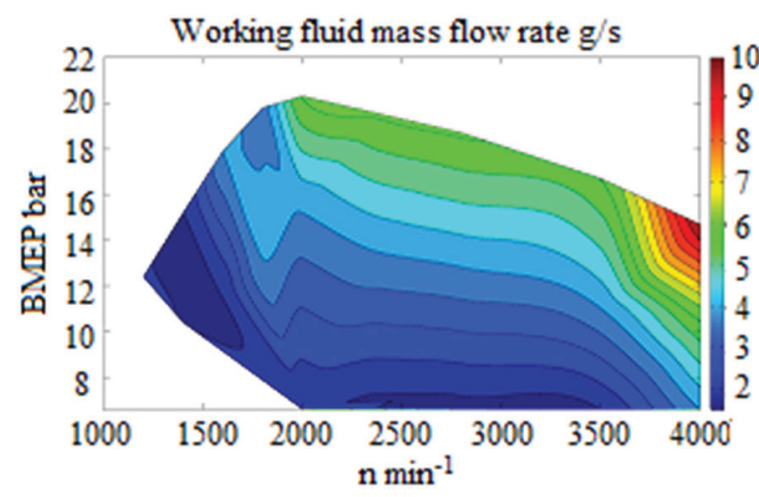

Fig. 20. Working fluid mass flow rate over the engine operating map.

The working fluid pressure variation is shown in Fig. 21. The optimal pressure varies from 5 bar to 20 bar. As it can be seen on the graph the working fluid pressure of 20 bar is optimal in large area on the engine map.

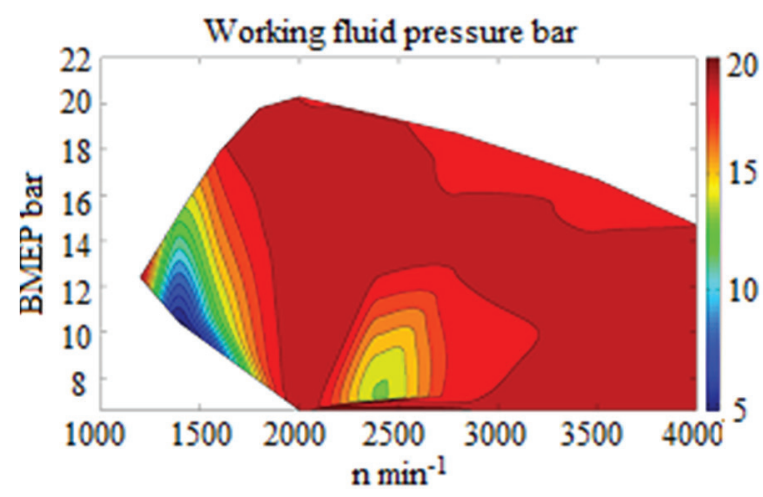

Fig. 21. Working fluid pressure over engine operating map.

\section{Conclusions}

Studied waste heat recovery system based on the Rankin cycle does not allow complete evaporation of the working fluid at all engine operating points. In the case of low energy of the exhaust gases, it is not possible to fully evaporate the working fluid.

The efficiency of the evaporator prototype varies from $25 \%$ to $51,9 \%$ in the studied engine operating range. The maximum efficiency was in the area with the maximum engine efficiency.

The variation of the working fluid thermal power after the evaporator depends on the exhaust gases energy at the evaporator inlet and increases with increasing engine speed and load.

On the basis of the experimental test, the optimal values for the mass flow rate and pressure of the working fluid in the system based on the Rankin cycle were determined.

The experimental study which is presented in this article was done at the Laboratoire du Chimie Moléculaire, Génie des Procédés, Chimiques et Energétiques (CMGPCE) - Cnam Paris.

\section{References}

1. M. Podhorsky and H. Krips, Heat exchangers : a practical approach to mechanical construction, design and calculations, NewYork, Wallingford, UK: Begell House Inc, (1998)

2. T. Kuppan, Heat exchangers design handbook, New York: Marcel Dekker, Inc., (2000)

3. Y. Glavatskaya, Conversion de l'énergie thermique des gaz d'échappement en travail mécanique par un cycle de Rankine afin de réduire les émissions des gaz à effet de serre, $\mathrm{PhD}$ thesis, (2012)

4. Q. Danel, Étude numérique et expérimentale d'un cycle de Rankine-Hirn de fable puissance pour la récupération d'énergie, $\mathrm{PhD}$ thesis, (2016)

5. V. Pandiyarajan, M.C. Pandian, E. Malan, R. Velraj, R.V. Seeniraj, Experimental investigation on heat recovery from diesel engine exhaust using finned shell and tube heat exchanger and thermal storage system, Applied Energy, 88(1), 77-87, (2011)

6. S. Lee and C. Bae, Design of a heat exchanger to reduce the exhaust temperature in a spark-ignition engine, Int. Journal of Thermal Sciences, 47(4), 468478, (2008)

7. H. Zhang, E. Wang, B. Fan, Heat transfer analysis of a finned-tube evaporator for engine exhaust heat recovery, Energy Conversion and Management, 65(0), 438-447, (2013)

8. M. Ghazikhani, M. Hatami, D. Ganji, M. GorjiBandpy, A. Behravan, G. Shahi, Exergy recovery from the exhaust cooling in a DI diesel engine for BSFC reduction purposes, Energy, 65(0), 44-51, (2014)

9. T. Wang, Y. Zhang, J. Zhang, G. Shu, Z. Peng, Analysis of recoverable exhaust energy from a lightduty gasoline engine, Applied Thermal Engineering, 53(2), 414-419, (2013)

10. S. Hossain, S. Bari, Waste heat recovery from the exhaust of a diesel generator using Rankine Cycle, Energy Conversion and Management, 75(0), 141-151, (2013)

11. S. Bari, S. Hossain, Waste heat recovery from a diesel engine using shell and tube heat exchanger, Applied Thermal Engineering, 61(2), 355-363, (2013)

12. S. Bai, H. Lu, T. Wu, X. Yin, X. Shi, L. Chen, Numerical and experimental analysis for exhaust heat exchangers in automobile thermoelectric generators, Case Studies in Thermal Engineering, 4(0), 99-112, (2014)

13. J. Dong, X. Zhang, J. Wang, Experimental investigation on heat transfer characteristics of plat heat exchanger applied in organic Rankine cycle $(O R C)$, Applied Thermal Engineering, 112, 11371152, (2017) 